University of New Hampshire

University of New Hampshire Scholars' Repository

Jackson Estuarine Laboratory

Institute for the Study of Earth, Oceans, and

Space (EOS)

$2-1-2002$

\title{
Modulation of swimming in the gastropod Melibe leonina by nitric oxide
}

Winsor $\mathrm{H}$. Watson III

University of New Hampshire, Durham, win.watson@unh.edu

James M. Newcomb

University of New Hampshire, Durham

Follow this and additional works at: https://scholars.unh.edu/jel

\section{Recommended Citation}

Newcomb, J. M. and W. H. Watson III. 2002. Modification of swimming in the gastropod Melibe leonine by nitric oxide. J. exp. Biol. 205: 397-403. http://jeb.biologists.org/node/1060211.full

This Article is brought to you for free and open access by the Institute for the Study of Earth, Oceans, and Space (EOS) at University of New Hampshire Scholars' Repository. It has been accepted for inclusion in Jackson Estuarine Laboratory by an authorized administrator of University of New Hampshire Scholars' Repository. For more information, please contact Scholarly.Communication@unh.edu. 


\title{
Modulation of swimming in the gastropod Melibe leonina by nitric oxide
}

\author{
James M. Newcomb ${ }^{1,2, *}$ and Winsor H. Watson III ${ }^{1,2}$ \\ ${ }^{1}$ Zoology Department and Center for Marine Biology, University of New Hampshire, Durham, NH 03824, USA and \\ ${ }^{2}$ Friday Harbor Laboratories, University of Washington, Friday Harbor, WA 98250, USA \\ *Present address: Department of Biology, Georgia State University, PO Box 4010, Atlanta, GA 30302-4010, USA \\ (e-mail: biojnn@langate.gsu.edu)
}

Accepted 15 November 2001

\begin{abstract}
Summary
Nitric oxide (NO) is a gaseous intercellular messenger produced by the enzyme nitric oxide synthase. It has been implicated as a neuromodulator in several groups of animals, including gastropods, crustaceans and mammals. In this study, we investigated the effects of NO on the swim motor program produced by isolated brains and by semi-intact preparations of the nudibranch Melibe leonina. The NO donors sodium nitroprusside (SNP, $1 \mathrm{mmoll}^{-1}$ ) and $S$-nitroso- $N$-acetylpenicillamine (SNAP, $1 \mathrm{mmoll}^{-1}$ ) both had a marked effect on the swim motor program expressed in isolated brains, causing an increase

oxyhemoglobin, eliminated the effects of NO donors on isolated brains, supporting the assumption that the changes in swimming induced by donors were actually due to NO. The cGMP analogue 8-bromoguanosine $3^{\prime}, 5^{\prime}$-cyclic monophosphate $\left(1 \mathrm{mmoll}^{-1}\right)$ produced effects that mimicked those of NO donors, suggesting that NO is working via a cGMP-dependent mechanism. These results, in combination with previous histological studies indicating the endogenous presence of nitric oxide synthase, suggest that NO is used in the central nervous system of Melibe leonina to modulate swimming.
\end{abstract} in the period of the swim cycle and a more erratic swim rhythm. In semi-intact preparations, the effect of NO donors was manifested as a significant decrease in the rate of actual swimming. An NO scavenger, reduced
Key words: nitric oxide, modulation, Melibe leonina, swimming, central pattern generator, cyclic GMP, gastropod, nudibranch.

\section{Introduction}

Nitric oxide (NO) is a gaseous molecule that serves as an intercellular messenger in the central nervous system (CNS) (Garthwaite et al., 1988). It is synthesized by the enzyme nitric oxide synthase (NOS), which converts L-arginine to Lcitrulline, releasing NO in the process. NO is a membranepermeable gas and thus easily diffuses from NOS-containing neurons into nearby target cells, where it usually binds to the heme group of cytosolic guanylate cyclase and causes enzyme activation (Ignarro, 1990; Southam and Garthwaite, 1993). Unlike typical neurotransmitters that only have to travel across a synaptic cleft, NO has to diffuse a greater distance to interact with cytosolic guanylate cyclase in neighboring cells. Park et al. (1998) demonstrated in culture that an NO-producing cell from the buccal ganglia of Lymnaea stagnalis was able to affect a follower cell up to $40 \mu \mathrm{m}$ away. This relatively large sphere of influence suggests that NO would be most suitably used as a neuromodulator, since the effects of such compounds generally have a slower time course than neurotransmitters (Harris-Warrick, 1988).

NO appears to modulate rhythmic activity in various groups of animals. For example, in the crustacean Cancer productus, NO is required for functional division of the stomatogastric ganglion into the pyloric and gastric mill rhythms (Scholz et al., 2001) and also modulates the cardiac ganglion (N. L. Scholz, personal communication). NO also mediates excitatory input to the central pattern generator (CPG) controlling respiration in the amphibian Rana catesbeiana (Hedrick and Morales, 1999), modulates locomotion in Xenopus laevis larvae (McLean and Sillar, 2000) and controls the functional state of oscillatory activity in mammalian thalamocortical neurons (Pape and Mager, 1992). In molluscs, NO is involved in feeding and locomotion in Clione limacina (Moroz et al., 2000), in the regulation of feeding in Aplysia californica (Lovell et al., 2000), in foodattraction conditioning in Helix pomatia (Teyke, 1996), in chemosensory activation of feeding in Lymnaea stagnalis (Moroz et al., 1993; Elphick et al., 1995) and in the oscillation of olfactory neurons in the procerebral lobe in Limax maximus (Gelperin, 1994). Since gastropods express a number of rhythmic behaviors (e.g. feeding, breathing, crawling and swimming) that are controlled by relatively simple CPGs, they offer very suitable model systems for investigating how NO modulates the rhythmic circuits underlying specific behaviors.

We have previously demonstrated the presence of two nitrergic cells in the CNS of the gastropod Melibe leonina, 
using both immunocytochemistry and NADPH-diaphorase histochemistry (Newcomb and Watson, 2001). These two bilaterally symmetrical cells are located in the cerebropleural ganglia and project into the ipsilateral pedal ganglia. While most of the interneurons involved in swim central pattern generators ( $\mathrm{sCPGs)}$ in gastropods often reside in the cerebral ganglia, the swim motoneurons (SMNs) are usually situated in the pedal ganglia (Getting et al., 1980; Arshavsky et al., 1985; McPherson and Blankenship, 1991; Gamkrelidze et al., 1995; Jing and Gillette, 1999). In Melibe leonina, the pedal ganglia contain two of the four identified sCPG interneurons and all the SMNs (Lawrence, 1997; Newcomb and Watson, 2000; Watson et al., 2001). The fact that the axons of the two NOS-containing cells project into the pedal ganglia suggests that NO might modulate swimming or other forms of locomotion in Melibe leonina.

In Melibe leonina, isolated brains readily express a swim rhythm (hereafter referred to as 'fictive swimming'). It is also possible to record from identified neurons in semi-intact preparations while the animals are exhibiting swimming behavior. These features make it possible to examine the modulation of fictive swimming in isolated brains and to gain insight into the effects of nitrergic neuromodulation on actual swimming behavior. In this paper, we report that NO donors decrease the rate of both fictive swimming and actual swimming and that this decrease can be eliminated in the presence of the NO scavenger reduced oxyhemoglobin. Furthermore, we found that a cGMP analogue mimics the effects of $\mathrm{NO}$, indicating that $\mathrm{NO}$ is probably acting via a cGMP-dependent mechanism. These results suggest that $\mathrm{NO}$ is used in the CNS of Melibe leonina to modulate swimming.

\section{Materials and methods \\ Preparation of oxyhemoglobin}

Reduced oxyhemoglobin was prepared from commercial bovine oxidized hemoglobin (met-hemoglobin) by reduction with sodium hydrosulfite. A Sephadex G-25 column $(52 \mathrm{~cm} \times 1.6 \mathrm{~cm})$ was equilibrated with $20 \mathrm{mmol}^{-1}$ phosphate buffer (PB, pH 7.0) containing $1 \mathrm{mmol}^{-1}$ EDTA. Sodium hydrosulfite $\left(2 \mathrm{ml} ; 0.57 \mathrm{~mol}^{-1}\right)$, dissolved in $\mathrm{PB}$, was added to the column, followed by another $1 \mathrm{ml}$ of PB. Then, $200 \mathrm{mg}$ of met-hemoglobin were dissolved in $10 \mathrm{ml}$ of $\mathrm{PB}$, added to the column and eluted with $\mathrm{PB}$ at a flow rate of $0.46 \mathrm{ml} \mathrm{min}{ }^{-1}$. The met-hemoglobin changed from brown to red as it passed through the lighter sodium hydrosulfite and was reduced. Reduced hemoglobin $(8 \mathrm{ml})$ was collected in an LKB Bromma 2212 Helirac fraction collector. The reduced hemoglobin was saturated with oxygen gas and dialyzed overnight against oxygen-saturated seawater. The concentration of oxyhemoglobin was determined by measuring its absorption at $415 \mathrm{~nm}$ using a Milton Roy Spectronic 601 and dividing by the extinction coefficient for hemoglobin $\left(131 \times 10^{3} \mathrm{~m}^{-1} \mathrm{~cm}^{-1}\right)$. Oxyhemoglobin was divided into $1-\mathrm{ml}$ samples and stored at $-20{ }^{\circ} \mathrm{C}$ until use.

\section{Animal collection and maintenance}

Adult Melibe leonina (Gould) were collected from subtidal eelgrass beds near the University of Washington's Friday Harbor Laboratories (FHL) on San Juan Island, WA, USA, by the authors and David Duggins and also from Patricia Bay in Saanich Inlet, British Columbia, Canada, by WestWind SeaLab Supplies (Victoria, British Columbia, Canada). Experiments were carried out at FHL, where Melibe leonina were kept in flow-through seawater tables at ambient temperature (approximately $10^{\circ} \mathrm{C}$ ), and at the University of New Hampshire, where they were maintained in recirculating seawater tanks at $10^{\circ} \mathrm{C}$. All Melibe leonina were anesthetized by chilling prior to dissection.

\section{Isolated brains}

Brains $(N=33)$ were removed from Melibe leonina by cutting all nerve roots except for the pedal-pedal connectives that travel around the ventral surface of the esophagus. Isolated brains were pinned in a Sylgard-lined, 2-ml recording dish and perfused with seawater. Coolant or ambient seawater was circulated through a surrounding aluminum plate to keep the recording chamber at $8-12{ }^{\circ} \mathrm{C}$. Intracellular electrodes, filled with $2 \mathrm{moll}^{-1}$ potassium acetate $(20-50 \mathrm{M} \Omega$ ), were used to record from SMNs in the pedal ganglia. These SMNs were identified by position (center of the dorsal surface of the pedal ganglia) and their characteristic rhythmic bursting activity (Watson et al., 2001). Intracellular amplifiers (A-M Systems, Inc. Neuroprobe Amplifier, model 1600, and Dagan 8700 Cell Explorer) were used to obtain these recordings, and their output was viewed on an oscilloscope and recorded on an Astro-Med, Inc. Dash IV chart recorder.

Initial experiments were conducted with NO donors [sodium nitroprusside (SNP) and $S$-nitroso- $N$-acetylpenicillamine (SNAP)] to determine the lowest dose that would yield consistent responses. The resulting concentration, $1 \mathrm{mmoll}^{-1}$, was used for all subsequent experiments. NO donors (SNP, $N=12$ brains; SNAP, $N=9$ brains) were added to the recording chamber while recording from SMNs. When the effects of the donors on the swim motor program had stabilized, preparations were washed with fresh seawater to determine whether the effects were reversible. Control experiments were also carried out for each NO donor (SNP, $N=6$ brains; SNAP, $N=3$ brains) by pre-incubating $200 \mu \mathrm{l}$ of $0.75 \mathrm{mmoll}^{-1}$ reduced oxyhemoglobin with an equivalent volume of $1 \mathrm{mmol}^{-1} \mathrm{SNP}$ or SNAP for $15 \mathrm{~min}$ before applying the NO donor to the preparation. In separate experiments, the cGMP analogue 8bromoguanosine $3^{\prime}, 5^{\prime}$-cyclic monophosphate (8-Br-cGMP; $N=3$ brains) was added at a final concentration of $1 \mathrm{mmoll}^{-1}$ (after previous experiments had indicated that this was the lowest dose that yielded consistent responses).

\section{Semi-intact preparations}

Semi-intact preparations $(N=3)$ were used to determine the behavioral correlates of fictive swimming both before and after the addition of NO donors. These preparations were carried out using a technique similar to that used by Willows 
to study swimming in Tritonia (Willows, 1967; Willows et al., 1973). Animals were suspended in a 3-1 chamber by hooks and threads attached to their dorsal integument, and the chamber was continuously perfused with natural seawater. A small opening was made in the skin just over the brain, and the brain was then immobilized by pinning it to a small waxcovered platform. This made it possible to obtain intracellular recordings from neurons in the brain while also allowing the animals to swim.

SNP $\left(1 \mathrm{mmol}^{-1}\right)$ was used in the semi-intact preparations in the same manner as in the isolated brains to determine the effects of NO donors on swimming. In addition to recording the bursting activity of the SMNs, the movements of each animal were simultaneously recorded with Hi-8 videography or a photonic sensor. The period of the actual swim rhythm and the rhythm of the SMNs were calculated by averaging 10 swim cycles before, during and after the addition of SNP. A swim cycle was designated as the time from the initiation of one burst to the beginning of the next burst. All results are presented as means \pm S.E.M.

\section{Results \\ Isolated brains}

The SMNs in the brains of Melibe leonina are located in the pedal ganglia (Fig. 1A). Contralateral SMNs fire in antiphase with each other, producing a swim pattern characterized by alternating left SMN/right SMN rhythmic bursting (Fig. 1B). In isolated preparations, fictive swimming occurs spontaneously and consistently, possibly as a result of the elimination of inhibitory feedback from the foot after removal of the brain from the animal. The consistent expression of the swim pattern provides an excellent preparation for testing the effects of various modulators on the sCPG.

Addition of SNP caused an increase in burst duration, interburst interval and swim cycle period (Fig. $2 \mathrm{~A}, N=12$ ). The usually consistent rhythm associated with fictive swimming also became more erratic. The threshold concentration for these effects was $1 \mathrm{mmoll}^{-1}$. Higher concentrations of SNP $\left(>1 \mathrm{mmoll}^{-1}\right)$ eliminated the swim rhythm entirely. The disruption of fictive swimming by a suprathreshold concentration of SNP was not immediate, but generally took 1.5-3 min to become apparent. The effects were reversible by washing the preparation with seawater, with a normal swim rhythm returning after $15-30 \mathrm{~min}$ (Fig. 2A). When SNP was applied at $1 \mathrm{mmoll}^{-1}$ with reduced oxyhemoglobin $\left(0.75 \mathrm{mmol}^{-1}\right)$, there was no effect on fictive swimming (Fig. 2B, $N=6$ ).

Addition of SNAP to isolated brains produced effects that were similar to those elicited by SNP (Fig. 3A, $N=9$ ). The threshold concentration $\left(1 \mathrm{mmol}^{-1}\right)$ and latency to cause an effect $(1.5-3 \mathrm{~min})$ were also similar to those of SNP. The effects on fictive swimming induced by SNAP were also reversible after a seawater wash for 15-30 min (Fig. 3A). As with SNP, control preparations with reduced oxyhemoglobin present showed no change in fictive swimming (Fig. 3B, $N=3$ ).
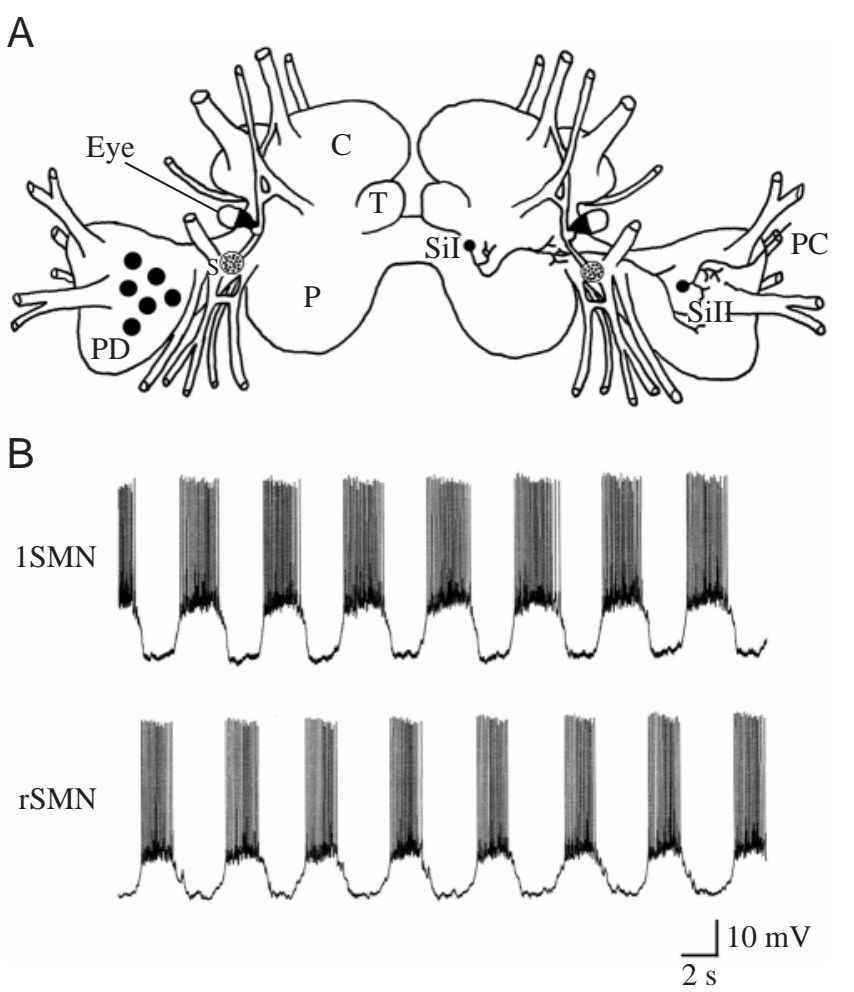

Fig. 1. (A) Drawing of the brain of Melibe leonina. The two fused ganglia that constitute most of the brain are the cerebral (C) and pleural (P) ganglia (also referred to jointly as the cerebropleural ganglia). Near the large commissure that connects the two halves of the brain are the paired tentacular lobes $(\mathrm{T})$. The left and right pedal ganglia (PD) are lateral to the cerebropleural ganglia. Interneurons of the swim central pattern generator (CPG) are indicated on the right half of this drawing (although the CPG is actually bilateral). Swim interneuron I (SiI) is located in the cerebropleural ganglion. It projects to the ipsilateral pedal ganglion, where it synapses on swim interneuron II (SiII) and swim motoneurons (indicated as filled circles in the left pedal ganglion). SiII synapses with motoneurons in the ipsilateral pedal ganglion and with SiII and motoneurons in the contralateral pedal ganglion via the pedal connective (PC), which encircles the esophagus in vivo. S, statocyst. (B) Typical recording from swim motoneurons in an isolated brain. Contralateral motoneurons fire in anti-phase, producing the alternating rhythmic bursting pattern characteristic of fictive swimming. 1SMN, left swim motoneuron; rSMN, right swim motoneuron.

Perfusion of isolated brains with 8-Br-cGMP produced effects that were similar to those caused by the two NO donors (Fig. 4, N=3). The threshold concentration for 8-Br-cGMP was also the same as for the $\mathrm{NO}$ donors $\left(1 \mathrm{mmol}^{-1}\right)$. The disruption of fictive swimming was reversible, but only needed less than 5 min to return to normal after washing with seawater, as opposed to the 15-30 min wash required after perfusion with NO donors.

\section{Semi-intact preparations}

Addition of $1 \mathrm{mmoll}^{-1} \mathrm{SNP}$ to the brain of semi-intact preparations $(N=3)$ mimicked the results obtained in isolated 
A

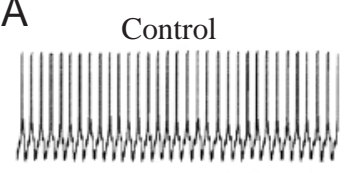

B

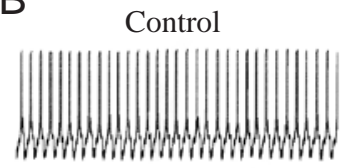

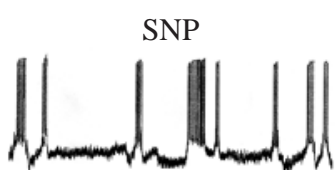

SNP with oxyhemoglobin

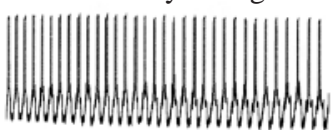

Wash

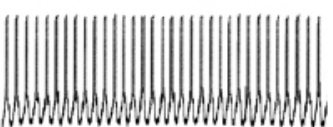

Wash

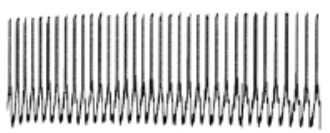

$\underset{10 \mathrm{~s}}{10 \mathrm{mV}}$

Fig. 2. Effects of sodium nitroprusside (SNP) on the swim motor program. (A) Control recording showing typical fictive swimming. Fifteen minutes after the addition of $1 \mathrm{mmol}^{-1} \mathrm{SNP}$, the period of the swim rhythm increased and became more erratic. This effect was reversible, as indicated by a return to a normal swimming pattern after a 23-min wash in seawater. (B) Reduced oxyhemoglobin blocked the effects of $1 \mathrm{mmoll}^{-1}$ SNP. This confirms that the effects from SNP were in fact due to NO and not to some other chemical property of the NO donor. All recordings were from the same cell.
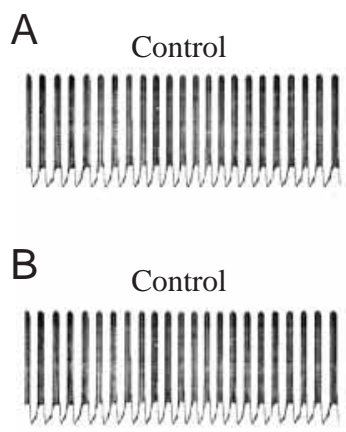

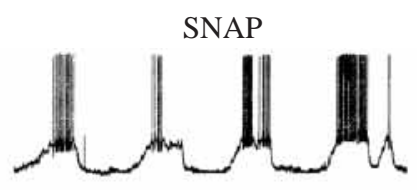

SNAP with oxyhemoglobin

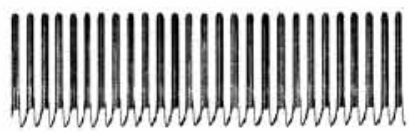

Wash

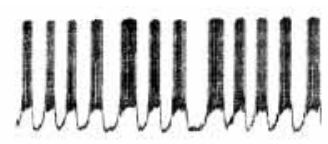

Wash

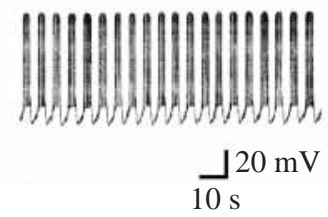

Fig. 3. Effects of $S$-nitroso- $N$-acetylpenicillamine (SNAP) on the swim motor program. (A) Control recording showing typical fictive swimming. Seven minutes after the addition of $1 \mathrm{mmol}^{-1}$ SNAP, the period of the swim rhythm increased and became more erratic. This effect was not completely reversible, as indicated by a gradual return to a shorter swim cycle and a more consistent bursting pattern after a 20 min wash in seawater. (B) Reduced oxyhemoglobin blocked the effects of $1 \mathrm{mmol}^{-1}$ SNAP. All recordings were from the same cell.
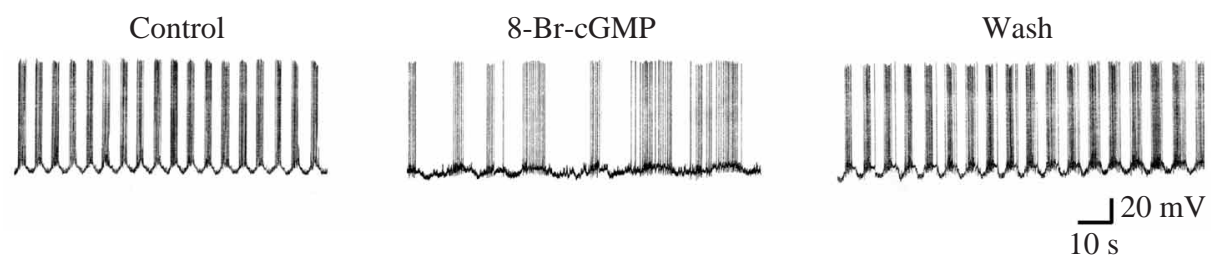

Fig. 4. Effects of 8-bromoguanosine 3',5'-cyclic monophosphate (8-Br-cGMP) on the swim motor program. The control recording showing typical fictive swimming. Six minutes after the addition of 1 mmol $1^{-1} 8$-Br-cGMP, the pattern changed to one with a longer swim cycle and less consistency in the pattern. These effects were totally reversible after only a 2-min wash in seawater. This pattern was similar to the results with the NO donors and is thus suggestive of the involvement of a cGMP-dependent pathway in modulation of the swim central pattern generator by NO. All recordings were from the same cell.

brains. The period of the swim rhythm increased significantly in SMNs (from $4.9 \pm 0.3$ to $8.8 \pm 1.3 \mathrm{~s} \mathrm{cycle}^{-1}, t$-test, $P<0.05$ ), and this was correlated with a significant increase in the period of actual swim cycles in semi-intact animals (from $4.9 \pm 0.3$ to $8.9 \pm 1.3 \mathrm{~s} \mathrm{cycle}^{-1}, t$-test, $P<0.05$ ) (Fig. 5). SNP took slightly longer to induce its effects in the semi-intact preparations (3-8 min) compared with the isolated brains $(1.5-3 \mathrm{~min})$, probably because of dilution in a larger volume of water. One of the three semi-intact preparations remained viable long enough to test the reversibility of the effects of SNP on swimming after washing in seawater. In this instance, the period of SMN bursting and actual swim cycles after a 5-min wash $\left(5.4 \mathrm{scycle}^{-1}\right.$ for both) had returned to control levels before the addition of SNP (5.4 $\mathrm{scycle}^{-1}$ ) (Fig. 5). 


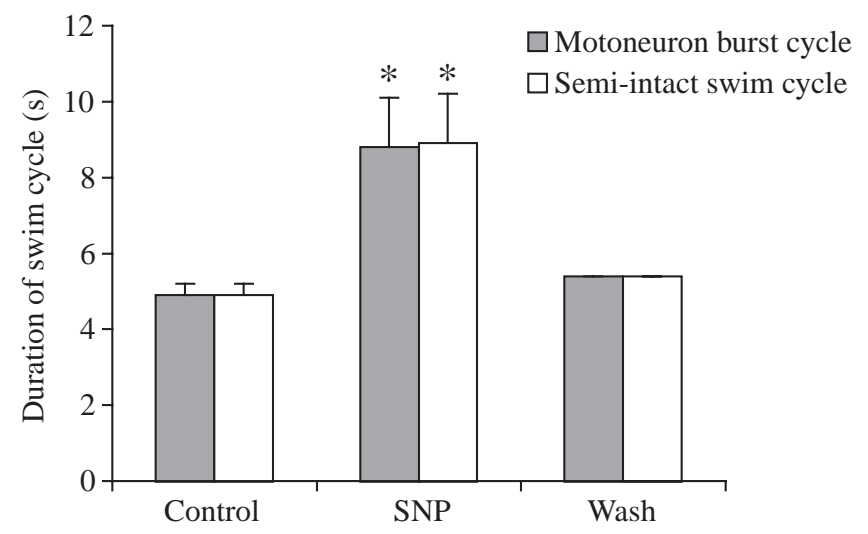

Fig. 5. Effects of sodium nitroprusside (SNP) on semi-intact preparations $(N=3)$. Video analysis of swimming in semi-intact preparations was correlated with motoneuron bursting recorded from the brain of the same animal. After the addition of SNP, the period of motoneuron bursting and actual swimming increased significantly from control levels $(t$-test, $P<0.05)$. In the single preparation that remained viable long enough, a 5-min wash in seawater resulted in a return to a normal swim period. Values are means \pm S.E.M. Asterisks indicate a significant difference from control values.

\section{Discussion}

In this study, SNP and SNAP both had marked effects on the swim motor program recorded from isolated Melibe leonina brains, causing an increase in the period of the swim cycle and a disturbance in the consistency of the rhythm (Figs 2, 3). Application of SNP to semi-intact preparations elicited the same results from SMNs, accompanied by a reduction in the rate of swimming (Fig. 5). These results suggest that nitrergic neurons may play a role in the modulation of swimming in intact Melibe leonina. In addition, perfusion of isolated brains with 8-Br-cGMP produced effects similar to those seen with $\mathrm{NO}$ donors (Fig. 4), suggesting that NO is working via a cGMP-dependent mechanism.

The concentrations of both NO donors $\left(1 \mathrm{mmoll}^{-1}\right)$ were comparable with those used in studies with other gastropods. Elphick et al. (1995) found that $1 \mathrm{mmol}^{-1}$ SNAP stimulated chemosensory activation of feeding in Lymnaea stagnalis, and $1 \mathrm{mmoll}^{-1}$ SNP and SNAP were used by Huang et al. (1998) to increase cGMP levels in target cells in neural ganglia of Helix pomatia. According to Ichimori et al. (1994), the estimated concentration of NO in $1 \mathrm{mmoll}^{-1}$ SNAP is approximately $1 \mu \mathrm{moll}^{-1}$, as measured by an NO-sensitive electrode. Moroz et al. (2000), in a study examining the effects of NO on feeding and locomotor circuitry in the pteropod mollusc Clione limacina, measured the amount of NO released by another NO donor, diethylamine NO complex sodium salt, at $0.05-0.2 \mathrm{mmol}^{-1}$. They found that threshold concentrations of NO proximal to neurons were $0.3-1 \mu \mathrm{moll}^{-1}$. NO-sensitive electrodes have also been used to measure endogenous production of $\mathrm{NO}$ in the brain of two other gastropods, where concentrations were found to be $0.01-0.05 \mu \mathrm{moll}^{-1}$ in the buccal ganglia of Lymnaea stagnalis and $0.03-0.1 \mu \mathrm{moll}^{-1}$ in the protocerebrum of Limax limacina (Moroz et al., 1995). All these studies indicate that millimolar concentrations of $\mathrm{NO}$ donors tend to release micromolar concentrations of $\mathrm{NO}$ at target sites and that these micromolar concentrations appear to be biologically relevant to the endogenous NO production from gastropod neurons.

In pharmacological studies with NO donors, it is important to be sure that the results are actually due to $\mathrm{NO}$ and not to other chemical properties or to breakdown products of the donor compounds. For example, SNP contains a ferricyanide group, which can interact with cellular components (Schuman and Madison, 1994). The heme group of reduced hemoglobin readily binds to paramagnetic molecules, such as oxygen, carbon monoxide and $\mathrm{NO}$, and has been demonstrated to readily scavenge NO (Miki et al., 1977; Knowles et al., 1989). Hemoglobin has also been used in similar gastropod preparations to control for the effects of NO (Elphick et al., 1995; Jacklet, 1995). In the present study, reduced oxyhemoglobin eliminated the effects of $\mathrm{NO}$ donors in isolated brains (Figs 2B, 3B), confirming that the changes in the swim rhythm elicited by SNP and SNAP were the result of NO and not any breakdown products of these compounds.

One of the distinctive features of our results was the time delay between the application of an NO donor and the resulting effects. This delay was $1.5-3 \mathrm{~min}$ in isolated brains and 3-8 min in semi-intact preparations. Some of this delay may have been due to the time required for diffusion of the NO donor through the connective tissue surrounding the brain. However, some of the delay may also be due to the mechanism of action of NO. Modulatory neurons often produce slowacting, dramatic effects that outlast the duration of modulatory neuron activation (McCrohan, 1988). For example, in the stomatogastric ganglion of the lobster Jasus lalandii, brief firing of the cholinergic anterior pyloric modulator (APM) interneuron, located in the esophageal ganglion, produces delayed and long-term alterations in the pyloric rhythm (Dickinson and Nagy, 1983; Nagy and Dickinson, 1983). Rather than acting at a single locus in the CPG, APM is thought to modify the properties of all the elements of the network (Nagy and Dickinson, 1983). Interestingly, this might also be the method of modulation used by a non-specific gaseous messenger such as NO.

It is not uncommon for sensory and modulatory systems to operate via second-messenger systems, such as pathways involving cGMP, cAMP or inositol trisphosphate. The kinetics of these pathways usually dictate a slower-acting time course than direct modification of ion channels. NO usually affects target cells by interacting with cytosolic guanylate cyclase and raising levels of intracellular cGMP (Ignarro, 1990; Southam and Garthwaite, 1993). However, NO can also act via cGMP-independent mechanisms, such as ADP-ribosylation of cytosolic proteins (Brune and Lapetina, 1989), and by binding to iron-sulfur centers of enzymes involved in the mitochondrial electron transport chain (Granger et al., 1980), the citric acid cycle (Drapier and Hibbs, 1986) and DNA synthesis (Nakaki et al., 1990). In addition, Hatcher et al. (2000) found that NO modulated 
cAMP-gated $\mathrm{Na}^{+}$currents in buccal neurons of Pleurobranchaea californica. In our study, we used a membrane-permeable, non-hydrolyzable cGMP analogue, 8Br-cGMP, to test for a cGMP-dependent mechanism of NO action. 8-Br-cGMP has been used in experiments with other molluscs, such as Clione limacina (Moroz et al., 2000) and the pond snail Lymnaea stagnalis (Elphick et al., 1995), in which it mimicked the effects observed with NO donors. Since our results with 8 -Br-cGMP also mimic the effects seen with NO donors, they suggest that NO is also working via a cGMP-dependent mechanism in Melibe leonina. In addition, recent experiments indicate that the soluble guanylate cyclase inhibitor $1 H$ - $(1,2,4)$-oxadiazolo $(4,3-$ a)quinoxalin-1-one (ODQ) blocks effects of SNP on the swim motor program (Newcomb et al., 2001).

Melibe leonina swim spontaneously, as well as when their foot is dislodged from the substratum, or to escape from noxious stimuli (Lawrence, 1997; Watson et al., 2001). The presence of prey increases feeding activity (Watson and Trimarchi, 1992; Watson and Chester, 1993), but also inhibits swimming (J. M. Newcomb and W. H. Watson III, personal observation), suggesting that the feeding CPG or a related component of the CNS may inhibit swimming under these circumstances. Since NO modulates swimming by decreasing the rate and consistency of swim cycles, it is possible that feeding-induced inhibition of swimming may be due to the release of NO. Inhibition between mutually exclusive neural networks is not unusual. For example, in Clione limacina, an interneuron involved in retraction of the parapodial wings (local withdrawal) also inhibits swimming (Huang and Satterlie, 1990), and in Pleurobranchaea californica, there is evidence suggesting that one of the functions of the A1 neurons of the $\mathrm{sCPG}$, in addition to generating the swim pattern, may be suppression of feeding behavior in response to noxious stimulation (Jing and Gillette, 1995). A1 spike activity in these animals suppresses fictive feeding in isolated brains as well as causing proboscis retraction in semi-intact animal preparations induced to feed (Jing and Gillette, 1995). Inhibition between command systems for feeding and escape behavior has also been demonstrated in crayfish (Krasne and Lee, 1988; Edwards, 1991). These studies indicate a tendency for neurons involved in mutually exclusive behaviors to inhibit each other at the neural level.

Moroz et al. (2000) have recently found evidence suggesting that NO is used as a neuromodulator in the swimming and feeding networks of Clione limacina. However, in contrast to our results with Melibe leonina, NO seems to play an excitatory role by activating both the swimming and feeding CPGs. This is not surprising when the feeding habits of these animals are considered. Melibe leonina remain stationary when they feed, whereas Clione limacina feed in the water column, and swimming is therefore stimulated by the presence of prey. In fact, an essential component of feeding behavior in Clione limacina is acceleration of swimming (Norekian, 1995). Melibe leonina and Clione limacina are the first two gastropods in which NO has been implicated as a modulator of locomotion, and these represent yet another example of modulation of a rhythmic behavior by NO.

In summary, SNP and SNAP decrease the rate of fictive swimming in isolated brains and actual swimming movements in semi-intact preparations. Experiments with 8-Br-cGMP yield results that mimic those seen with $\mathrm{NO}$ donors, suggesting that NO is working via a cGMP-dependent mechanism. This evidence suggests that NO is being used to modulate the sCPG of Melibe leonina, possibly to decrease the likelihood that swimming will occur during certain behavioral states such as feeding arousal. Future work involving the nitrergic cerebral neurons themselves and their interactions with the sCPG should further elucidate the role of NO in the CNS of Melibe leonina and shed light on the neuromodulatory functions of this unique gaseous intercellular messenger.

This research was supported by NIH grant NS36411 to W.H.W. and a Society for Integrative and Comparative Biology Grants-In-Aid of Research grant to J.M.N. The authors would like to thank David Duggins and Catherine Schnorr von Carolsfeld for collecting the animals, Edward Tillinghast for assistance with reducing hemoglobin and Dennis Willows for the use of his photonic sensor.

\section{References}

Arshavsky, Y. I., Beloozerova, I. N., Orlovsky, G. N., Panchin, Y. V. and Pavlova, G. A. (1985). Control of locomotion in marine mollusc Clione limacina. II. Rhythmic neurons of pedal ganglia. Exp. Brain Res. 58, 263-272.

Brune, B. and Lapetina, E. G. (1989). Activation of a cytosolic ADPribosyltransferase by nitric oxide-generating agents. J. Biol. Chem. 264, 8455-8458.

Dickinson, P. S. and Nagy, F. (1983). Control of a central pattern generator by an identified modulatory interneurone in Crustacea. II. Induction and modification of plateau properties in pyloric neurones. J. Exp. Biol. 105, 59-82.

Drapier, J. C. and Hibbs, J. B. (1986). Murine cytotoxic activated macrophages inhibit aconitase in tumor cells. Inhibition involves the iron-sulfur prosthetic group and is reversible. J. Clin. Invest. 78, 790-797.

Edwards, D. H. (1991). Mutual inhibition among neural command systems as a possible mechanism for behavioral choice in crayfish. J. Neurosci. 11, 1210-1223.

Elphick, M. R., Kemenes, G., Staras, K. and O'Shea M. (1995). Behavioral role for nitric oxide in chemosensory activation of feeding in a mollusc. $J$. Neurosci. 15, 7653-7664.

Gamkrelidze, G. N., Laurienti, P. J. and Blankenship, J. E. (1995). Identification and characterization of cerebral ganglion neurons that induce swimming and modulate swim-related pedal ganglion neurons in Aplysia brasiliana. J. Neurophysiol. 74, 1444-1462.

Garthwaite, J., Charles, S. L. and Chess-Williams, R. (1988). Endotheliumderived relaxing factor release on activation of NMDA receptors suggests a role as intracellular messenger in the brain. Nature 336, 385-388.

Gelperin, A. (1994). Nitric oxide mediates network oscillations of olfactory interneurons in a terrestrial mollusc. Nature 369, 61-63.

Getting, P. A., Lennard, P. R. and Hume, R. I. (1980). Central pattern generator mediating swimming in Tritonia. I. Identification and synaptic interactions. J. Neurophysiol. 44, 151-164.

Granger, D. L., Taintor, R. R., Cook, J. L. and Hibbs, J. B. (1980). Injury of neoplastic cells by murine macrophages leads to inhibition of mitochondrial respiration. J. Clin. Invest. 65, 357-360.

Harris-Warrick, R. M. (1988). Chemical modulation of central pattern generators. In Neural Control of Rhythmic Movements in Vertebrates (ed. A. Cohen, S. Rossignol and S. Grillner), pp. 285-331. New York: John Wiley \& Sons, Inc.

Hatcher, N. G., Thompson, S. H. and Gillette, R. (2000). Nitric oxide 
induces intracellular calcium release in feeding neurons of the sea slug, Pleurobranchaea. Soc. Neurosci. Abstr. 26, 918.

Hedrick, M. S. and Morales, R. D. (1999). Nitric oxide as a modulator of central respiratory rhythm in the isolated brainstem of the bullfrog (Rana catesbeiana). Comp. Biochem. Physiol. A 124, 243-251.

Huang, S., Kerschbaum, H. H. and Hermann, A. (1998). Nitric-oxide mediated cGMP synthesis in Helix neural ganglia. Brain Res. 780, 329-336.

Huang, Z. and Satterlie, R. A. (1990). Neuronal mechanisms underlying behavioral switching in a pteropod mollusc. J. Comp. Physiol. 166, 875-887.

Ichimori, K., Ishida, H., Fukahori, M., Nakazawa, H. and Murakami, E. (1994). Practical nitric oxide measurement employing a nitric oxideselective electrode. Rev. Sci. Instrum. 65, 2714-2718.

Ignarro, L. J. (1990). Nitric oxide: a novel signal transduction mechanism for transcellular communication. Hypertension 16, 477-483.

Jacklet, J. W. (1995). Nitric oxide is used as an orthograde cotransmitter at identified histaminergic synapses. J. Neurophysiol. 74, 891-895.

Jing, J. and Gillette, R. (1995). Neuronal elements that mediate escape swimming and suppress feeding behavior in the predatory sea slug Pleurobranchaea. J. Neurophysiol. 74, 1900-1910.

Jing, J. and Gillette, R. (1999). Central pattern generator for escape swimming in the notaspid sea slug, Pleurobranchaea californica. $J$. Neurophysiol. 81, 654-667.

Knowles, R. G., Palacios, M., Palmer, R. M. J. and Moncada, S. (1989). Formation of nitric oxide from L-arginine in the central nervous system: a transduction mechanism for stimulation of the soluble guanylate cyclase. Proc. Natl. Acad. Sci. USA 86, 5159-5162.

Krasne, F. B. and Lee, S. C. (1988). Response-dedicated trigger neurons as control points for behavioral actions: selective inhibition of lateral giant command neurons during feeding in crayfish. J. Neurosci. 8, 3703-3712.

Lawrence, K. A. (1997). Neuroethology of the swimming behavior in the Pacific nudibranch, Melibe leonina. PhD dissertation, University of New Hampshire.

Lovell, P. J., Kabotyanski, E. A., Sadreyev, R. I., Boudko, D. Y., Byrne, J. H. and Moroz, L. L. (2000). Nitric oxide activates buccal motor programs in Aplysia californica. Soc. Neurosci. Abstr. 26, 918.

McCrohan, C. R. (1988). Modification of central pattern generation in invertebrates. Comp. Biochem. Physiol. 90A, 17-22.

McLean, D. L. and Sillar, K. T. (2000). The distribution of NADPHdiaphorase-labelled interneurons and the role of nitric oxide in the swimming system of Xenopus laevis larvae. J. Exp. Biol. 203, 705-713.

McPherson, D. R. and Blankenship, J. E. (1991). Neural control of swimming in Aplysia brasiliana. I. Innervation of parapodial muscle by pedal ganglion motoneurons. J. Neurophysiol. 66, 1338-1351.

Miki, N., Kawabe, Y. and Kuriyama, K. (1977). Activation of cerebral guanylate cyclase by nitric oxide. Biochem. Biophys. Res. Commun. 75, 851-856.

Moroz, L. L., Norekian, T. P., Pirtle, T. J., Robertson, K. J. and Satterlie, R. A. (2000). Distribution of NADPH-diaphorase reactivity and effects of nitric oxide on feeding and locomotory circuitry in the pteropod mollusc, Clione limacina. J. Comp. Neurol. 427, 274-284.
Moroz, L. L., Park, J.-H. and Winlow, W. (1993). Nitric oxide activates buccal motor patterns in Lymnaea stagnalis. NeuroReport 4, 643-646.

Moroz, L. L., Radbourne, S. and Winlow, W. (1995). The use of NOsensitive microelectrodes for direct detection of nitric oxide (NO) production in molluscs. Acta Biol. Hung. 46, 155-167.

Nagy, F. and Dickinson, P. S. (1983). Control of a central pattern generator by an identified modulatory interneurone in Crustacea. I. Modulation of the pyloric motor output. J. Exp. Biol. 105, 33-58.

Nakaki, T., Nakayama, M. and Kato, R. (1990). Inhibition by nitric oxide and nitric oxide- producing vasodilators of DNA synthesis in vascular smooth muscle cells. Eur. J. Pharmacol. 189, 347-353.

Newcomb, J. M. and Watson III, W. H. (2000). Identifiable nitrergic cells in the central nervous system of Melibe leonina. Soc. Neurosci. Abstr. 26, 1166.

Newcomb, J. M. and Watson III, W. H. (2001). Identifiable nitrergic neurons in the central nervous system of the nudibranch Melibe leonina localized with NADPH-diaphorase histochemistry and nitric oxide synthase immunoreactivity. J. Comp. Neurol. 437, 70-78.

Newcomb, J. M., Goy, M., Turner, B. E. and Watson III, W. H. (2001). Modulation of the swim motor program in the gastropod Melibe leonina by cyclic GMP and cyclic AMP. Soc. Neurosci. Abstr. 27, Program No. 942.3.

Norekian, T. P. (1995). Prey capture phase of feeding behavior in the pteropod mollusc Clione limacina: neuronal mechanisms. J. Comp. Physiol. A 177, $41-53$.

Pape, H. C. and Mager, R. (1992). Nitric oxide controls oscillatory activity in thalamocortical neurons. Neuron 9, 441-448.

Park, J.-H., Straub, V. A. and O'Shea, M. (1998). Anterograde signaling by nitric oxide: characterization and in vitro reconstitution of an identified nitrergic synapse. J. Neurosci. 18, 5463-5476.

Scholz, N. L., de Vente, J., Truman, J. W. and Graubard, K. (2001). Neural network partitioning by NO and cGMP. J. Neurosci. 21, 1610-1618.

Schuman, E. M. and Madison, D. V. (1994). Nitric oxide and synaptic function. Anпи. Rev. Neurosci. 17, 153-183.

Southam, E. and Garthwaite, J. (1993). The nitric oxide-cyclic GMP signaling pathway in rat brain. Neuropharmacology 32, 1267-1277.

Teyke, T. (1996). Nitric oxide, but not serotonin, is involved in acquisition of food-attraction conditioning in the snail Helix pomatia. Neurosci. Lett. 206, 29-32.

Watson III, W. H. and Chester, C. M. (1993). The influence of olfactory and tactile stimuli on the feeding behavior of Melibe leonina (Gould, 1852) (Opisthobranchia: Dendronotacea). Veliger 36, 311-316.

Watson III, W. H., Lawrence, K. A. and Newcomb, J. M. (2001). Neuroethology of Melibe leonina. Am. Zool. 41, 1025-1034.

Watson III, W. H. and Trimarchi, J. (1992). A quantitative description of Melibe feeding behavior and its modification by prey density. Mar. Behav. Physiol. 19, 183-194.

Willows, A. O. D. (1967). Behavioral acts elicited by stimulation of single, identifiable brain cells. Science 157, 570-574.

Willows, A. O. D., Dorsett, D. A. and Hoyle, G. (1973). The neuronal basis of behavior in Tritonia. I. Functional organization of the central nervous system. J. Neurobiol. 4, 207-237. 